\title{
Activated Phosphatidylinositol 3-Kinase/ Akt Inhibits the Transition of Endothelial Progenitor Cells to Mesenchymal Cells by Regulating the Forkhead Box Subgroup 0-3a Signaling
}

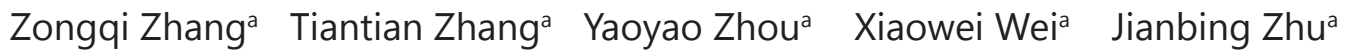
Junfeng Zhanga Changqian Wang ${ }^{b}$

aDepartment of Cardiology, No. 3 People's Hospital, Shanghai Jiao Tong University School of Medicine, Shanghai, bDepartment of Cardiology, Ninth People's Hospital, Shanghai Jiao Tong University School of Medicine, Shanghai, China

\section{Key Words}

Endothelial progenitor cell • Endothelial-to-mesenchymal transition • Phosphatidylinositol 3-kinase • PIK3R2 • FoxO3a

\begin{abstract}
Background and Aims: Endothelial progenitor cells (EPCs) differentiate into mature endothelial cells and may thus be candidates for ischemic disease therapy; however, the transition of EPCs to mesenchymal cells is not fully understood. We explored the role of phosphatidylinositol 3-kinase (PI3K)/Akt signaling in endothelial-to-mesenchymal transition (EndMT) induced by transforming growth factor beta 1 (TGF- $\beta 1$ ). Methods: Rat bone marrow-derived EPCs were isolated by using Ficoll-Isopaque Plus density-gradient centrifugation. EndMT was induced by TGF- $\beta 1(5 \mathrm{ng} / \mathrm{mL})$. PI3K/Akt signaling was activated by IGF-1 or Lenti-PIK3R2 shRNA. Additionally, FoxO3a expression was suppressed by a lentiviral vector (Lenti-FoxO3a shRNA). Smad3 and FoxO3a co-localization was detected by confocal immunofluorescence microscopy. The expressions of molecules involved in EndMT were exmined by using Westernblot analysis. Results: EndMT of EPCs was fully developed after TGF- $\beta 1$ treatment $(5 \mathrm{ng} / \mathrm{mL}$ ) for 7 days. PIK3R2 expression in EPCs was driven by TGF- $\beta 1$. Lenti-PIK3R2 shRNA blocked alpha-smooth muscle actin ( $\alpha-S M A)$ expression in EPCs treated with TGF- $\beta 1$, drove PI3K/Akt activation, and increased expression of phosphorylated FoxO3a instead of phosphorylated Smad3. The effect of Lenti-PIK3R2 shRNA was reduced by LY294002, a specific inhibitor of PI3K. IGF-1 attenuated $\alpha$-SMA protein expression in EPCs treated with TGF- $\beta 1$. Similar to LentiPIK3R2 shRNA, IGF-1 also inhibited and elevated the phosphorylation of Smad3 and FoxO3a, respectively. IGF-1 disrupted the co-localization of these proteins in EPCs treated with TGF- $\beta 1$. Lenti-FoxO3a shRNA transfection of EPCs suppressed expression of FoxO3a as well as that of
\end{abstract}

Z. Zhang and T. Zhang contributed equally to this work.

Dr. Junfeng Zhang

KARGER 125
Department of Cardiology, No. 3 People's Hospital, Shanghai Jiao Tong University School of Medicine, 280 Mohe Road, Shanghai 201900 (China)

Tel. +86 21 56691101-6260, Fax +86 21 56691662, E-Mail jfzhang_dr@163.com 


\section{Cellular Physiology Cell Physiol Biochem 2015;35:1643-1653

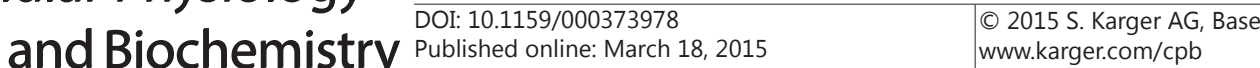

the mesenchymal markers SM22 $\alpha$ and $\alpha$-SMA. Conclusions: Activation of PI3K/Akt signaling by Lenti-PIK3R2 shRNA or by exogenous IGF-1 inhibits EndMT in EPCs via negative regulation of FoxO3a-dependent signaling.

Copyright (C) 2015 S. Karger AG, Basel

\section{Introduction}

Endothelial progenitor cells (EPCs) derived from the bone marrow (BM) play a protective role in cardiovascular disease and diabetes mellitus by migrating to the injured endothelium and differentiating into mature endothelial cells. However, BM-derived EPCs also differentiate into mesenchymal cells positive for alpha-smooth muscle actin ( $\alpha$-SMA), a process known as endothelial-to-mesenchymal transition (EndMT). EPCs may thus contribute to intimal hyperplasia during endothelial repair. For instance, BM-derived EPCs could migrate into the intimae of a balloon-injured carotid artery to augment intimal hyperplasia [1], which is secondary to the process of EndMT induced by transforming growth factor beta 1 (TGF- $\beta 1$ ) in the hypertrophic neointima [2]. Several studies have demonstrated neointimal hyperplasia inside EPC-capturing stents implanted in the coronary artery [3] or between the carotid artery and internal jugular vein [4], especially in patients with poorly controlled diabetes mellitus [5]. The mechanisms of EPCs in intimal hyperplasia have not been fully elucidated.

TGF- $\beta 1$ signaling through TGF- $\beta$ cell surface receptors induces EndMT in EPCs. By binding to TGF- $\beta$ receptor II (TGF $\beta$ RII), TGF- $\beta 1$ induces phosphorylation of Smad 2 and $\alpha$-SMA in EPCs, suggesting that the EndMT process is mediated by the TGF $\beta$ RII/Smad2 signaling pathway $[1,6]$. Several studies have shown that inhibition of TGF- $\beta$ receptor I (TGF $\beta R I$ ) inhibits snail gene expression, blocks EndMT, and facilitates differentiation of EPCs to the endothelial cell lineage, suggesting an essential role of TGF $\beta R I / S m a d 3$ in the EndMT of EPCs [2]. However, recent studies have shown that in the absence of TGF- $\beta 1$, physiological shear stress induces expression of $\alpha$-SMA in EPCs when treated with Wortmannin, a specific inhibitor of phosphatidylinositol 3-kinase (PI3K) [7]. These results suggest PI3K/Akt regulates EndMT in EPCs independent of TGF- $\beta 1$.

PI3K is a heterodimeric complex of regulatory and catalytic subunits, including p85 $(\alpha$, $\beta$, and $\gamma$ ) and p110. P85 $\beta$, i.e., PIK3R2, inhibits phosphorylation of Akt, which is subsequently activated by PI3K. The PI3K/Akt signaling pathway mediates many biological activities in EPCs including proliferation [8], endothelial differentiation [9], migration [10], senescence [11], and hormonal secretion [12]. However, the role of PI3K/Akt signaling in EndMT of EPCs is unclear.

In our previous study, we found that PIK3R2 expression increased and PI3K decreased in EPCs during the EndMT process [13]. Akt activation suppresses TGF- $\beta$ /ALK5-mediated Smad3 activation in an Akt kinase-dependent manner through mTOR in prostatic epithelial cells [14] or by inhibiting translocation of the Fox03/Smad3 transcription factor complex from the cytoplasm to the nucleus in neuroepithelial cells [15]. Activation of Smad3 also mediates EndMT in EPCs [2]. Therefore, we hypothesized that PI3K/Akt pathway activation in EPCs may inhibit the EndMT process.

In this study, we activated PI3K/Akt by suppressing PIK3R2 expression or by treating the cells with exogenous IGF- 1 and measured its effect on TGF- $\beta 1$-induced EndMT of BMderived EPCs. We also investigated the role of FoxO3a signaling in this pathway.

\section{Materials and Methods}

The investigation conformed to the principles outlined in the US National Institutes of Health guidelines for use of animal tissues and was approved by the Ethics Committee of Experimental Research, Shanghai Jiao Tong University School of Medicine. 


\section{Cellular Physiology Cell Physiol Biochem 2015;35:1643-1653 \begin{tabular}{l|l|l}
\hline DOI: 10.1159/000373978 & (C) 2015 S. Karger AG, Basel
\end{tabular} and Biochemistry Published online: March 18, $2015 \quad$ www.karger.com/cpb \\ Zhang et al.: PI3K/Akt Signaling Regulates EndMT of EPCS}

Cell isolation, identification, and culture

BM-derived EPCs were isolated from male Sprague-Dawley rats (300 to $450 \mathrm{~g}$ ) as described in our previous study [13]. We used Ficoll-Isopaque Plus (Histopaque-1077, Sigma) density-gradient centrifugation to isolate mononuclear cells from the rat bone marrow. After culture for 4-7 days in conditioned medium on fibronectin-coated dishes, non-adherent cells were removed with gentle washes of phosphate-buffered saline (PBS) and the attached cells were used in the following experiments. For identification, resuspended cells were incubated with PE-CD34 and FITC-KDR antibodies (Jackson IRL, Baltimore, MD); CD34+/KDR+ cells were identified as EPCs by flow cytometry (FACScan ${ }^{\circledR}$; BD Biosciences) and CellQuest software (BD Biosciences).

\section{Induction of EndMT}

Cells were seeded on culture plates with Ham's F-12 containing 5\% FBS; EndMT was induced by treatment with TGF- $\beta 1(5 \mathrm{ng} / \mathrm{mL})$ for 7 days [13]. To investigate the role of PI3K/Akt signaling in EndMT, EPCs were treated with IGF-1 (100 ng/mL, R\&D Systems, Minneapolis, MN; 4326-RG) plus TGF- $\beta 1$ for 7 days (activation), or with LY294002 (25 $\mu$ M, Cell Signaling Technology, Beverly, MA; catalog no. 9901) for $24 \mathrm{~h}$ to block PI3K/Akt. EPCs were transfected with PIK3R2 shRNA (Lenti-PIK3R2 shRNA; Santa Cruz Biotechnology, Santa Cruz, CA; catalog no. sc-39126-V) or FoxO3a shRNA (Lenti-FoxO3a shRNA; Santa Cruz Biotechnology; catalog no. sc-37888-V) according to manufacturer protocols, and stable clones expressing PIK3R2 shRNA or FoxO3a shRNA were selected for the following experiments.

Immunofluorescence

Cells were rinsed with PBS and fixed for $15 \mathrm{~min}$ at room temperature, then blocked for $2 \mathrm{~h}$ in PBS containing 5\% normal goat serum and 2\% BSA [13]. Monoclonal antibody (diluted 1:1000) against $\alpha$-SMA (Millipore Corporation, Billerica, MA; catalog no. CBL171) or CD31 (Santa Cruz Biotechnology; catalog no. sc-376764) was incubated with the fixed and permeabilized cells for $2 \mathrm{~h}$, followed by five rinses with PBS. The cells then were incubated with Alexa Fluor 594-conjugated Goat anti-mouse antibody (diluted 1:500) for $1 \mathrm{~h}$.

Confocal microscopy was used to detect translocation of Smad3/FoxO3a. Fixed cells were incubated with primary antibodies for anti-Smad3 (Santa Cruz Biotechnology; catalog no. sc-101154) and anti-Fox03a (Cell Signaling Technology; catalog no.2497s), then with Alexa Fluor 488 Goat Anti-Mouse (diluted 1:500) and Alexa Fluor 594 Goat Anti-Rabbit antibody (diluted 1:500). Nuclei were stained with $1 \mu \mathrm{g} / \mathrm{mL}$ DAPI for $5 \mathrm{~min}$ at room temperature.

\section{Western blot analysis}

Proteins were prepared from cell lysates as described [13], separated by 10\% SDS-PAGE, electrophoretically transferred to PVDF membranes, and probed with primary antibody followed by horseradish peroxidase-conjugated secondary antibody (HRP). The primary antibodies for western blot analysis were as follows: anti-PIK3R2 (Santa Cruz Biotechnology; catalog no. sc-131324), anti-PI3K (Cell Signaling Technology; catalog no. 4249S), anti-p-Akt (Cell Signaling Technology; catalog no. 9271S), antiAKT (Cell Signaling Technology; catalog no. 9272S), anti-SM22 $\alpha$ (Santa Cruz Biotechnology; catalog no. sc134794), anti- $\alpha$-SMA (Millipore Corporation; catalog no. CBL171), anti-CD31 (Santa Cruz Biotechnology; catalog no. sc-376764), anti-FoxO3 (Cell Signaling Technology; catalog no. 2497s), anti-p-FoxO3 (Santa Cruz Biotechnology; catalog no. sc-101683), anti-Smad3 (Santa Cruz Biotechnology; catalog no. sc-101154), antip-Smad3 (Cell Signaling Technology; catalog no. 9520s) and anti- $\beta$-actin (Cell Signaling Technology; catalog no. 8456). The membranes were developed with enhanced chemiluminescence reagent for visualization.

Statistical analysis

SPSS 13.0 software was used for statistical analysis. Data are expressed as the mean \pm SD, and analyzed by ANOVA followed by least significant difference (LSD) t-test for post-hoc comparison.

\section{Results}

PI3K/Akt signaling was involved in EndMT of EPCs

After 7-day treatment with TGF- $\beta 1$, EPCs morphologically changed from a cobblestonelike to a spindle-shaped appearance (Fig. 1A) with cytoplasmic $\alpha$-SMA expression and loss KARGER 
Fig. 1. TGF- $\beta 1$-induced EPCs underwent EndMT. A) Morphological changes in EPCs after treatment with TGF- $\beta 1$ ( $5 \mathrm{ng} / \mathrm{mL}$ ) for 7 days (original magnification $\times 200$ ). B) Protein expression of endothelial cell markers (CD31) and mesenchymal cell markers ( $\alpha$-SMA) in TGF$\beta 1$-induced EPCs was determined by immunofluorescence staining.

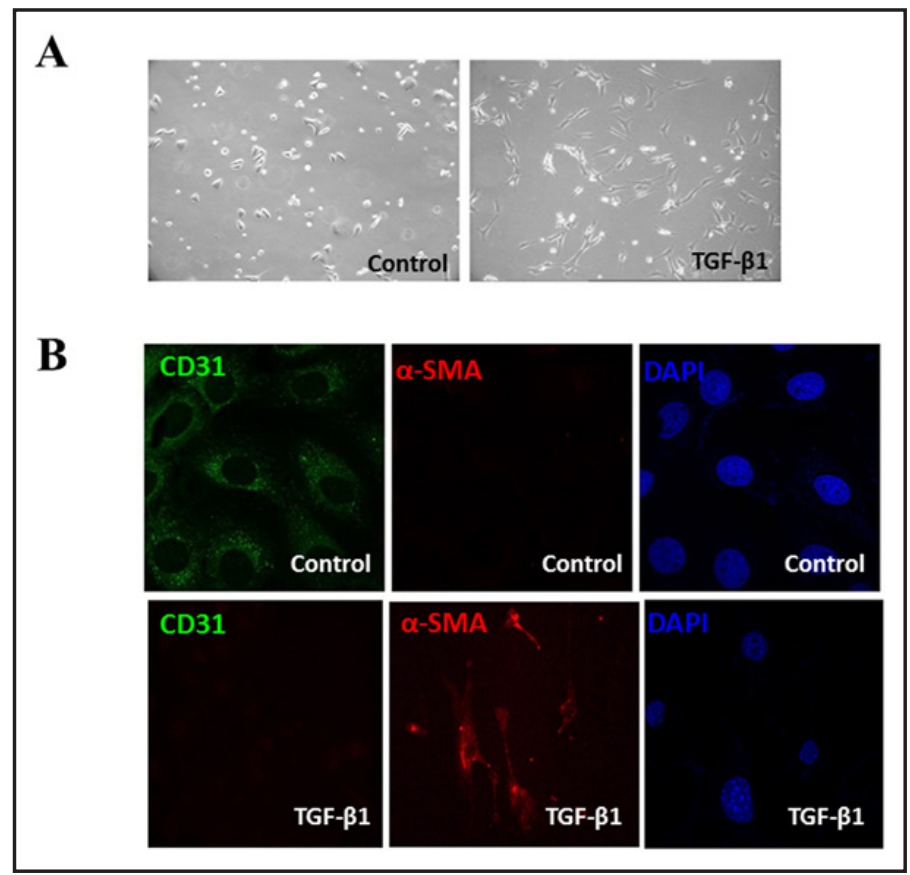

Fig. 2. PIK3R 2 and $\alpha$-SMA expression in EPCs treated with TGF- $\beta 1$. (A) Protein expression of PIK3R2 and $\alpha$-SMA was detected by western blotting. (B) Relative expression was determined by densitometry $(\mathrm{n}=5)$. Lane 1 , Untreated EPCs; Lane 2, EPCs treated with TGF- $\beta 1$ (5 $\mathrm{ng} / \mathrm{mL}$ ); Lane 3, EPCs transfected with PIK3R2 shRNA (Lenti-PIK3R2 shRNA); Lane 4, EPCs transfected with Lenti-PIK3R2 shRNA and treated with TGF- $\beta 1$ ( $5 \mathrm{ng} / \mathrm{mL})$; Lane 5 , EPCs were transfected with control PIK3R2 shRNA (Lenti-control shRNA) and treated with TGF- $\beta 1$ (5 $\mathrm{ng} / \mathrm{mL}$ ); Lane 6, EPCs transfected with Lenti-PIK3R2 shRNA and pretreated with LY294002 for $24 \mathrm{~h}$, followed by treatment with TGF- $\beta 1$ (5 ng/ $\mathrm{mL})$. Data are shown as mean $\pm \mathrm{SD}$. ${ }^{*} \mathrm{P}<0.05$ vs. control EPCs (Lane 1); ${ }^{\#} \mathrm{P}<0.05$ vs. EPCs treated with Lenti-control shRNA plus TGF- $\beta 1$ (Lane 5). The number of observations (n) represents the number of independent cell preparations.

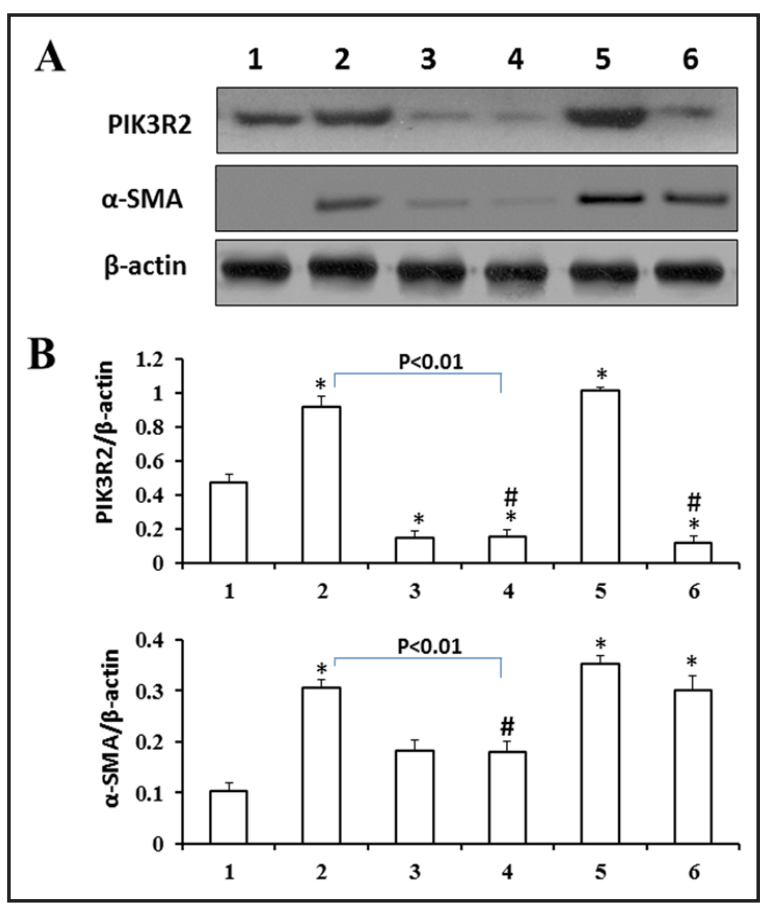

of CD31 (Fig. 1B). PIK3R2 shRNA was used to block PIK3R2 expression in this study. Similar to the results from our previous study [13], Lenti-PIK3R2 shRNA blocked $\alpha$-SMA expression in EPCs treated with TGF- $\beta 1$. And $\alpha$-SMA expression was restored by LY294002, a specific inhibitor of PI3K (Fig. 2).

Suppression of PIK3R2 activated PI3K/Akt to regulate FoxO3a signaling during EndMT of EPCS

EPCs exhibited basal levels of PI3K and phosphorylated Akt that were decreased by TGF- $\beta 1$, however, were not affected by Lenti-PIK3R2 shRNA in absence of TGF- $\beta 1$ (Fig. 3). TGF- $\beta 1$ inhibition of PI3K and phosphorylated Akt was reversed by Lenti-PIK3R2 shRNA to 


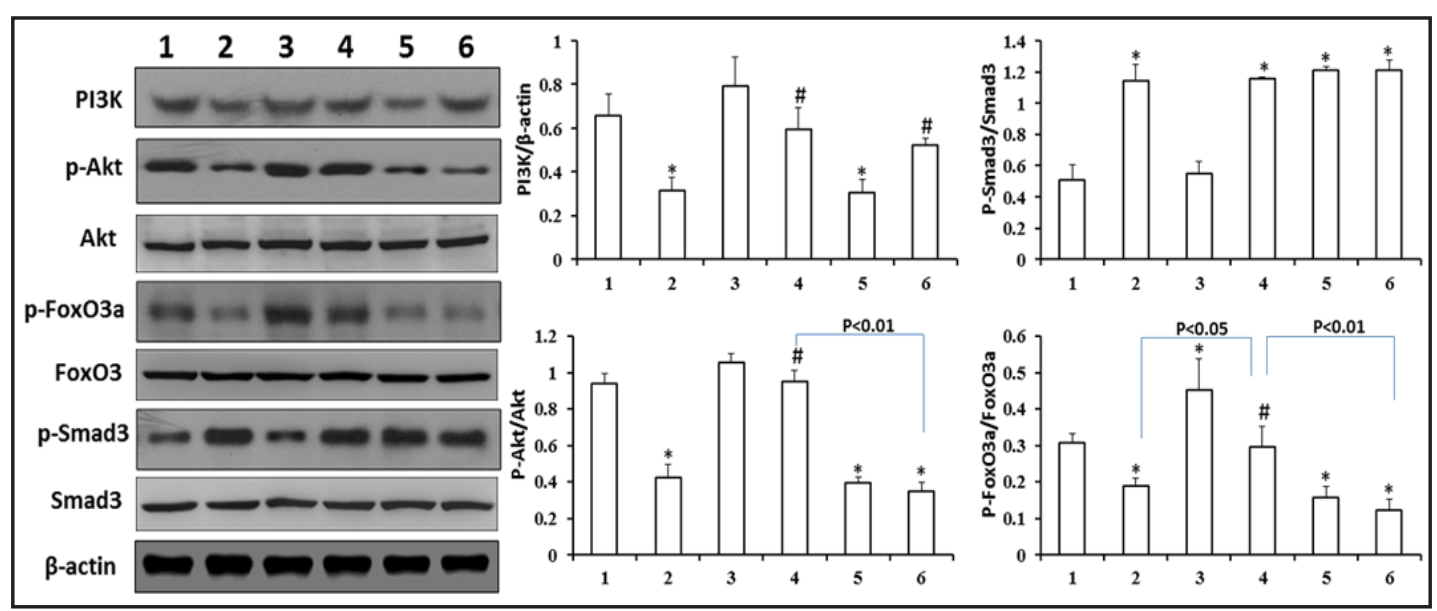

Fig. 3. Suppression of PIK3R2 expression activated PI3K/Akt to regulate FoxO3a signaling in EndMT of EPCs. Protein expression of PI3K, Akt, phosphorylated Akt, Smad3, phosphorylated Smad3, FoxO3a, and phosphorylated Fox03a was examined by western blotting. Relative expression levels were determined by densitometry $(n=5)$. $\beta$-actin was used as an internal control. Lane 1, untreated EPCs; Lane 2, EPCs treated with TGF- $\beta 1$ (5 ng/mL); Lane 3, EPCs transfected with PIK3R2 shRNA (Lenti-PIK3R2 shRNA); Lane 4, EPCs transfected with Lenti-PIK3R2 shRNA and then treated with TGF- $\beta 1$ (5 ng/mL); Lane 5, EPCs transfected with control PIK3R2 shRNA (Lenti-control shRNA) and then treated with TGF- $\beta 1(5 \mathrm{ng} / \mathrm{mL})$; Lane 6, EPCs transfected with Lenti-PIK3R2 shRNA and pretreated with LY294002 for $24 \mathrm{~h}$, then with TGF- $\beta 1(5 \mathrm{ng} / \mathrm{mL})$. Data are shown as mean $\pm \mathrm{SD}$. ${ }^{*} \mathrm{P}<0.05$ vs. control EPCs (Lane 1 ); ${ }^{*} \mathrm{P}<0.05$ vs. EPCs treated with Lenti-control shRNA plus TGF- $\beta 1$ (Lane 5). The number of observations (n) represents the number of independent cell preparations.

the basal level (Fig. 3). In untreated EPCs, there was a basal expression of phosphorylated FoxO3a that was increased by Lenti-PIK3R2 shRNA. Phosphorylations of Smad3 and FoxO3a were elevated and decreased in EPCs treated with TGF- $\beta 1$, respectively. In spite of the presence of TGF- $\beta 1$, the phosphorylation of FoxO3a in EPCs was increased by Lenti-PIK3R2 shRNA, however, there was no effect on the phosphorylation of Smad3 (Fig. 3). The increase in phosphorylated FoxO3a expression induced by Lenti-PIK3R2 shRNA was nearly reversed by LY294002 (Fig. 3).

IGF-1 inhibited EndMT and activated PI3K/Akt in EPCS

Compared to the untreated EPCs, IGF-1 induced a notable increase of the expression of PI3K and phosphorylated Akt in EPCs (Fig. 4). IGF-1 attenuated $\alpha$-SMA protein expression and increased PI3K and phosphorylated Akt levels in EPCs treated with TGF- $\beta 1$ (Fig. 4).

\section{IGF-1 inactivated Smad3/FoxO3a signaling during EndMT of EPCs}

TGF- $\beta 1$ induced and inhibited phosphorylation of Smad3 and FoxO3a, respectively; such an effect of TGF- $\beta 1$ was suppressed by IGF-1(Fig. 4). To explore the role of IGF-1 in regulating Smad3/FoxO3a activation, the translocation of Smad3/FoxO3a was detected by confocal fluorescence microscopy. Untreated EPCs showed cytoplasmic and nuclear expression of Smad3 and FoxO3a, but no co-localization. TGF- $\beta 1$ induced translocation of Smad3 and FoxO3a from the cytoplasm to the nucleus, followed by co-localization; these effects were reversed by IGF-1 (Fig. 5).

\section{FoxO3a mediated EndMT in EPCs}

To evaluate the role of Fox03a in EndMT, we suppressed its expression in EPCs with Lenti-FoxO3a shRNA (Fig. 6). Lenti-FoxO3a shRNA also reduced expression of SM22 $\alpha$, a 


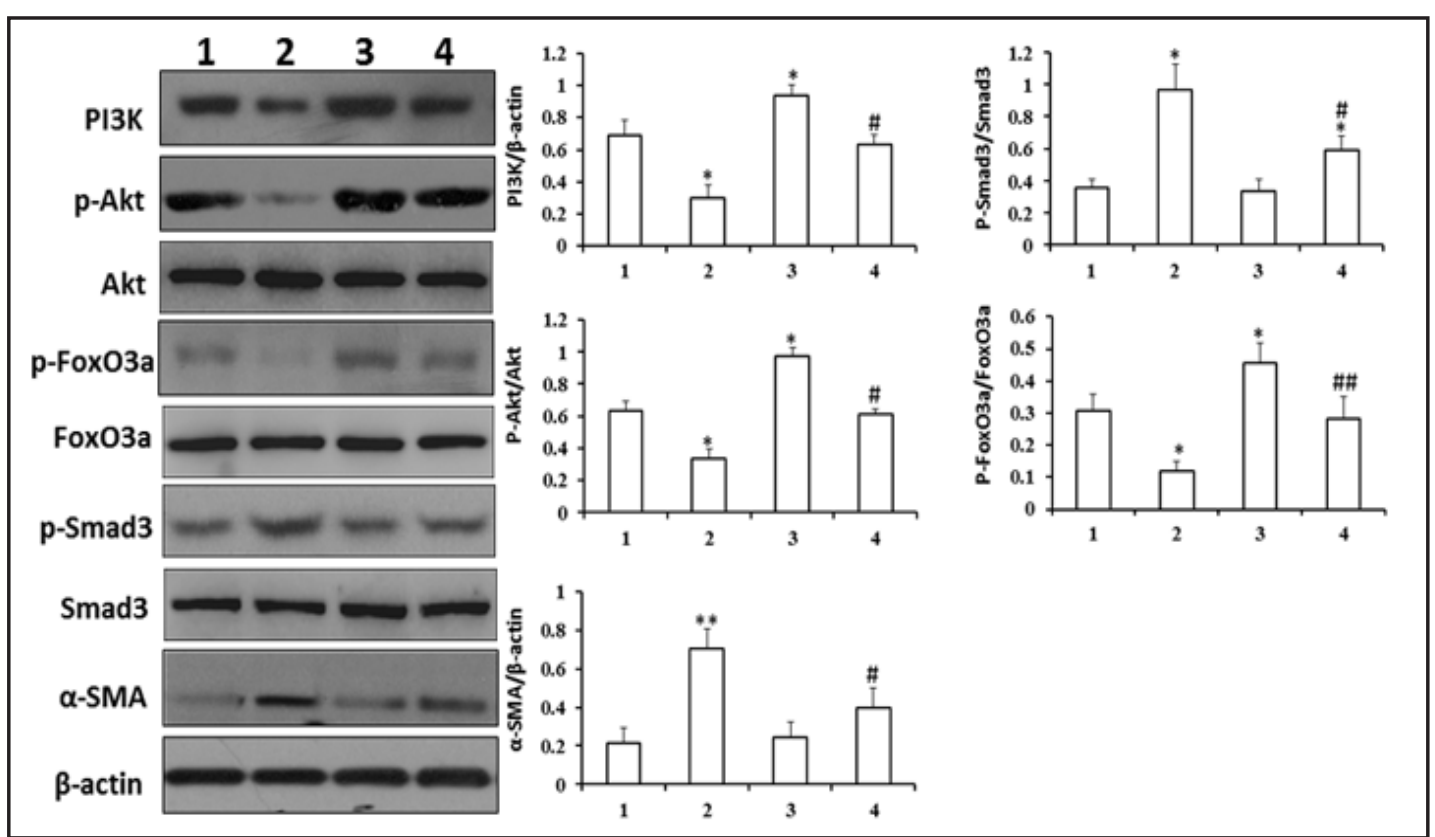

Fig. 4. IGF-1 inhibited EndMT and activated PI3K/Akt in EPCs. After treatment with TGF- $\beta 1$ ( $5 \mathrm{ng} / \mathrm{mL}$ ) or/ plus IGF-1 (100 ng/mL) for 7 days, EPC proteins were prepared and immunoblotting assays were performed using specific antibodies against $\alpha$-SMA, PI3K, phosphor-Akt, Akt, FoxO3a, phosphor-FoxO3a, and Smad3. $\beta$-actin was used as the internal control. Relative protein levels were determined by densitometry $(n=5)$. Lane 1, untreated EPCs; Lane 2, EPCs treated with TGF- $\beta 1$ (5 ng/mL); Lane 3, EPCs treated with IGF-1(100 $\mathrm{ng} / \mathrm{mL})$; Lane 4, EPCs treated with TGF- $\beta 1$ (5 ng/mL) plus IGF-1(100 ng/mL). Data are shown as mean \pm SD. Untreated EPCs were used as a control. ${ }^{*} \mathrm{P}<0.05$ vs. control EPCs; ${ }^{\#} \mathrm{P}<0.05$; ${ }^{\# \#} \mathrm{P}<0.01$ vs. EPCs treated with TGF- $\beta 1$. The number of observations (n) represents the number of independent cell preparations.

Fig. 5. IGF-1 inactivated the Smad3/FoxO3a signaling pathway in EndMT of EPCs. Intracellular location and expression of FoxO3a and Smad3 were determined by confocal immunofluorescence microscopy. Untreated EPCs were used as controls. Green, Smad3; Red, FoxO3a; Blue, nuclear staining with DAPI. Co-localization of Fo$\mathrm{xO3a}$ and Smad3 is marked with a yellow arrow. Nuclear expression of FoxO3a is marked with a red arrow.

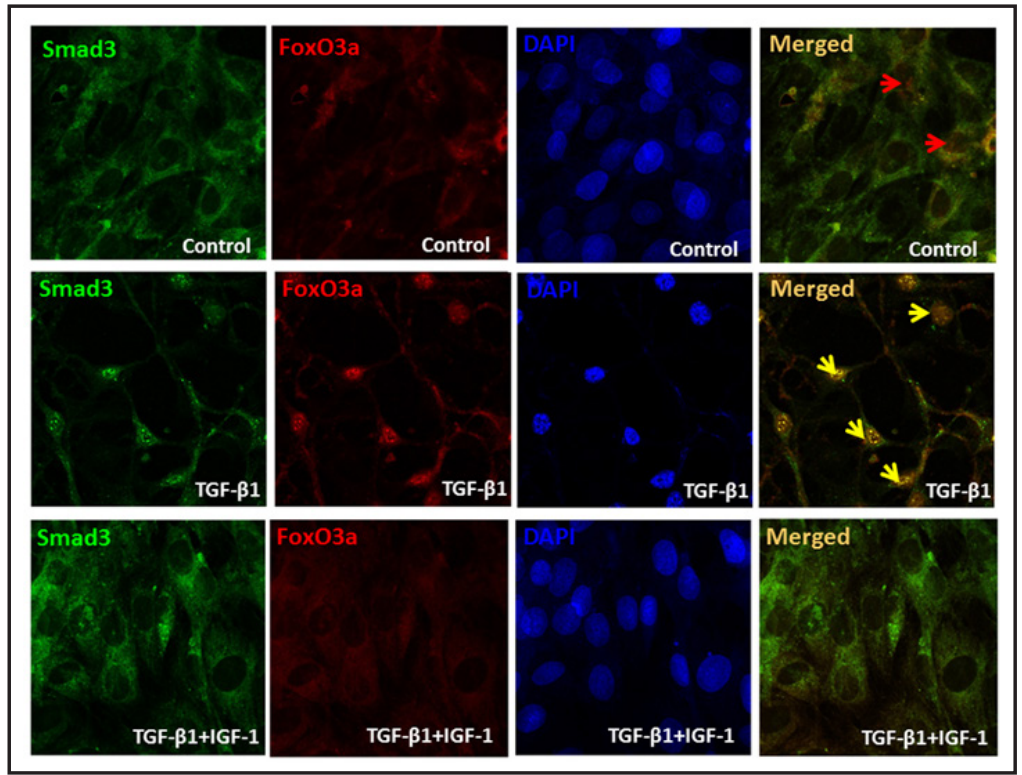

marker of mesenchymal cells (Fig. 6A). Immunofluorescence assays showed that increase of $\alpha$-SMA expression in EPCs treated with TGF- $\beta 1$ was inhibited by Lenti-FoxO3a shRNA, which alone did not affect SM22 $\alpha$ and $\alpha$-SMA expression in normal control EPCs (Fig. 6B). 


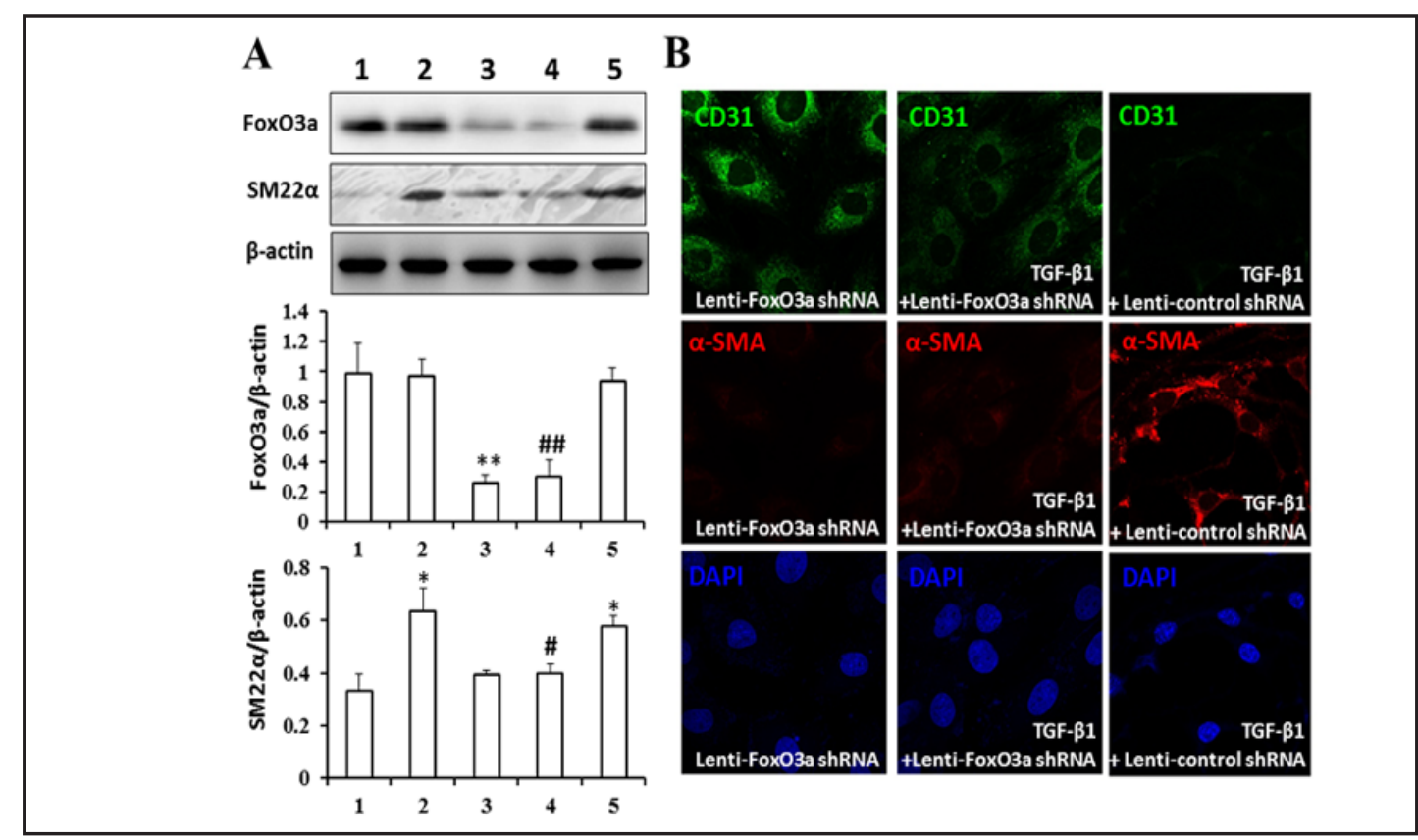

Fig. 6. FoxO3a mediated the EndMT process of EPCs. (A) Protein expression of Fox03a and sm22- $\alpha$ was detected by immunofluorescence staining. Relative protein levels were determined by densitometry $(\mathrm{n}=$ 5). $\beta$-Actin was used as an internal control. Data are shown as mean \pm SD. Lane 1, untreated EPCs; Lane 2, EPCs treated with TGF- $\beta 1$ ( $5 \mathrm{ng} / \mathrm{mL}$ ); Lane 3, EPCs transfected with FoxO3a shRNA (Lenti-FoxO3a shRNA); Lane 4, EPCs transfected with Lenti-FoxO3a shRNA and then treated with TGF- $\beta 1$ ( $5 \mathrm{ng} / \mathrm{mL}$ ); Lane 5, EPCs transfected with control FoxO3a shRNA (Lenti-control shRNA) and then treated with TGF- $\beta 1$ (5 ng/mL). * $\mathrm{P}<0.05 ;{ }^{* *} \mathrm{P}<0.01$ vs. control EPCs; ${ }^{\#} \mathrm{P}<0.05$; ${ }^{\# \#} \mathrm{P}<0.01$ vs. EPCs treated with Lenti-control shRNA plus TGF- $\beta 1$ (Lane 5). The number of observations (n) represents the number of independent cell preparations. (B) Expression of endothelial cell markers (CD31, Green) and mesenchymal cell markers ( $\alpha$-SMA, Red) in TGF- $\beta 1$-induced EPCs was determined by immunofluorescence staining.

\section{Discussion}

EPCs have been long thought to differentiate into ECs and are thus considered potential candidates for the treatment of ischemic diseases. However, accumulating evidence has shown that transition of EPCs into the smooth muscle cell lineage, i.e., EndMT, aggravates the intimal hyperplasia that contributes to atherogenesis. Although TGF- $\beta 1 \mathrm{R}$-dependent Smad signaling was believed to be responsible for EndMT of EPCs $[2,6]$, previous studies showed that EPC expression of $\alpha$-SMA in vitro was induced by shear stress without TGF- $\beta 1$ [7] and that only half of EPCs transplanted to impaired endothelium underwent the EndMT process [1], suggesting that the process could be regulated. Our results showed that increased PIK3R2 suppresses activation of PI3K/Akt and plays a pivotal role in the regulation of EndMT of EPCs. Inhibition of PIK3R2 expression by Lenti-PIK3R2 shRNA or exogenous IGF-1 activates PI3K/Akt and inhibits EndMT by inactivating FoxO3a signaling in EPCs (Fig. 7).

PI3K is a pivotal growth factor signal composed of a p85 repressive regulatory subunit and a p110 catalytic subunit. By means of its major product phosphatidylinositol 3,4,5-trisphosphate (PIP3), PI3K conveys signals from receptor tyrosine kinases to downstream targets such as Akt/protein kinase B and the atypical protein kinase Cs that play essential roles in cellular protein synthesis, growth, and differentiation [16]. P85 $\beta$, encoded by the PIK3R2 gene, is involved in various cellular processes such as migration [17], proliferation, and survival [18]. In this study, PIK3R2 levels increased in EPCs stimulated with TGF- $\beta 1$; blockade of PIK3R2 expression by Lenti-PIK3R2 shRNA suppressed expression of $\alpha$-SMA, suggesting PIK3R2 contributes to EndMT. 
Fig. 7. A model of the regulation of activated PI3K/ Akt in EndMT process of EPCs by a FoxO3a-dependent manner. When EPCs are treated by TGF- $\beta 1$, Smad2/3 is phosphorylated and forms the complex with Smad4, driving FoxO3a to translocate into nucleus from cytoplasm. Then the complex of Smad2/3/4 interacts with Fox03a to initiate EndMT process. PI3K/Akt signaling, which is activated or inhibited by IGF-1 or PIK3R2 respectively, acts as a suppressor on the translocation of FoxO3a from cytoplasm to nucleus in the EndMT process of EPCs. Red solid or dash arrow line represents the positive or negative effect, respectively.

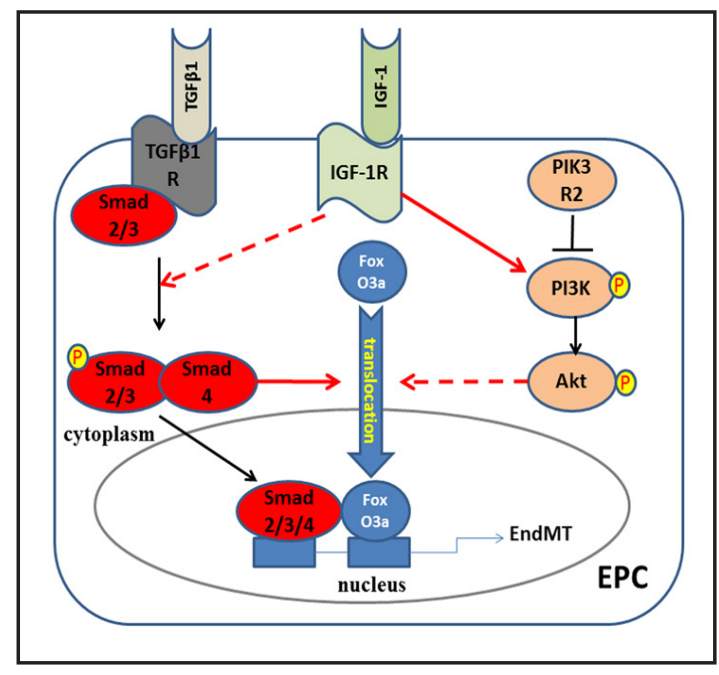

Although the mechanisms of PIK3R2 regulation of PI3K activation are not fully understood, it is believed that PIK3R2 forms a p85-p110 complex, thus stabilizing the labile p110 and inhibiting its catalytic activity. Other proteins, such as PTEN, specifically bind to the p85 subunit to dephosphorylate PI3K [19]. Furthermore, deletion of PIK3R2 significantly increased insulin-induced Akt activation [20], consistent with our finding that shRNA suppression of PIK3R2 induced expression of phosphorylated Akt in EPCs treated by TGF- $\beta 1$.

PI3KR2 is essential to regulating insulin signaling by inactivating PI3K-dependent downstream targets such as Akt and Erk $[20,21]$. However, many studies have shown that PIK3R2 binds other proteins such as X-box binding protein-1 [16] and focal adhesin kinase [17] to activate downstream targets in a PI3K-independent manner. In our study, the shRNA inhibition of $\alpha$-SMA expression was reversed by LY294002, suggesting PIK3R2 intensifies the EndMT process of EPCs via the PI3K-dependent Akt signaling pathway.

Insulin-like growth factor 1 (IGF-1) is a small 7.7-KDa polypeptide that activates the PI3K/Akt signaling pathway. IGF-1 induced phosphorylation of PI3K and Akt, and inhibited TGF- $\beta 1$-driven $\alpha$-SMA expression. These results suggest PI3K/Akt activation inhibits the EndMT process of EPCs.

Several studies have demonstrated that TGF- $\beta 1 \mathrm{R}$-dependent Smad signaling mediates EndMT of EPCs $[2,6]$ and Smad2 or Smad3 mediate transduction of TGF- $\beta 1$ R-dependent signaling [1, 6]. Indeed, expression of phosphorylated Smad3 increased markedly in EPCs undergoing EndMT in this study. Notably, the basal level of phosphorylated Akt in EPCs was increased significantly by IGF-1, instead of Lenti-PIK3R2 shRNA. And it was IGF-1, not LentiPIK3R2 shRNA, that repressed Smad3 phosphorylation, suggesting that the effects of activated PI3K/Akt on Smad3 phosphorylation were dependent of the level of Akt phosphorylation in EPCs in the process of EndMT. The current results appear to be inconsistent with the previous results that Akt interacts directly with unphosphorylated Smad3 to prevent its phosphorylation in Hep3B cells line through a mechanism that is independent of Akt kinase activity [22], suggesting that the crosstalk of PI3K/Akt with Smad3 signaling is cell-specific.

The forkhead box subgroup 0 (FoxO) transcription factor family is one of the most important downstream targets of the PI3K/Akt pathway and plays an important role in regulating diverse cellular functions such as apoptosis, differentiation, metabolism, proliferation, and survival [23]. In this study, Lenti-FoxO3a shRNA completely abolished the expression of $\alpha$-SMA and SM $22 \alpha$ in EPCs, indicating that FoxO3a-dependent signaling was necessary for the EndMT process.

FoxO3a is a substrate of protein kinase Akt. In the absence of cellular stimulation and when Akt is inactive, Fox03a is localized within the nucleus where it drives transcription of target genes; it is translocated to the cytoplasm upon phosphorylation FoxO3 [24]. In this study, untreated EPCs expressed basal levels of phosphorylated FoxO3a that increased KARGER 


\section{Cellular Physiology Cell Physiol Biochem 2015;35:1643-1653 and Biochemistry POI: 10.1159/000373978 $\quad$ C 2015 S. Karger AG, Base \\ Zhang et al.: PI3K/Akt Signaling Regulates EndMT of EPCS}

with Lenti-PIK3R2 shRNA or IGF-1; however, the effect was nearly abolished by TGF- $\beta 1$, suggesting that FoxO3a is the hinge of PI3K/Akt and TGF- $31 /$ Smad3 signaling during EndMT in EPCs.

We observed nuclear expression of Fox03a and cytoplasmic expression of Smad3. TGF- $\beta 1$ induced nuclear co-localization of FoxO3a and Smad3, consistent with prior results showing that FoxO3a forms a complex with Smad3 or Smad4 instead of Smad2 to block the transcription factor p21, playing an essential role in the cellular cycle [15]. Recent studies showed that epithelial cells were more inclined to mesenchymal transition upon loss of p21 [25, 26], suggesting a prohibitory role of p21 in epithelial-to-mesenchymal transition. However, the role of p21 in EndMT needs to be explored further. In this study, co-localization of FoxO3a and Smad3 was completely disrupted by IGF-1, suggesting that PI3K/Akt disrupts the Smad3/FoxO3a complex and inactivates the TGF- $\beta 1 /$ Smad3 signaling pathway responsible for the EndMT of EPCs.

Notablely, phosphorylated FoxO3a by PI3K/Akt signaling, was recently proved to bind the promoter of YAP, and then activated Hippo/YAP signaling [27]. And the activation of Hippo/YAP signaling was previously demonstrated to promote the cytoplasmic translocation of Smad3 from nuleues to relay cell density information in TGF- $\beta$-mediated epithelial-tomesenchymal transition [28]. These results suggested that activated PI3K/Akt signaling might induce the FoxO3a phosphorylation to activate Hippo/YAP signaling, and then to inhibit Smad3 signaling in EndMT of EPCs, which will be explored in the future studies.

One of the limitations of our study is that we did not explore the roles of other Smad proteins in the EndMT of EPCs, such as Smad4, which also binds FoxO3a [15], suggesting that activated PI3K/Akt phosphorylates FoxO3a to inhibit Smad4-dependent signaling in EPCs undergoing the process of EndMT. However, previous study showed that the common mediator Smad4 binds to Smad1/5, and might faciliate the inhibition of bone morphogenetic protein-7 to EndMT of endothelial cells [29]. These discrepant results indicate a complicated role of Smad4 in EndMT of EPCs that needs to be investigated further.

In addition, IGF-1 activates Erk1/2-MAPK signaling [30] and Erk1/2 is activated by PI3K/ Akt [31]. Suppression of Erk1/2 phosphorylation upregulates Smad2/3 phosphorylation and enhances cellular differentiation [32]. These results and those of our study suggest a potential role of Erk1/2 in the activation of PI3K/Akt and suppression of Smad3-dependent signaling in the EndMT of EPCs. This hypothesis will be tested in future studies.

In summary, activation of PI3K/Akt via suppression of PIK3R2 or exogenous IGF-1 inhibited EndMT. This inhibition likely occurred by regulating gene expression through the FoxO3a/Smad3 transcription complexes and revealed the pivotal role of PI3K/Akt in the regulation of EndMT of EPCs.

\section{Acknowledgements}

This work was supported by Innovation Program of Shanghai Municipal Education Commission [12YZ045 to ZQ Zhang] and the Shanghai Municipal Natural Science Foundation [12ZR1417400 to JF Zhang]. It was further supported by National Natural Science Foundation of China[81200206 to ZQ Zhang], the Doctoral Fund of Ministry of Education of China [20110073120096 to ZQ Zhang], Science and Technology Commission Foundation of Baoshan District in Shanghai [11-E-5 to ZQ Zhang] and Science and Technology Foundation from Shanghai Jiao-Tong University School of Medicine[11XJ21031 to ZQ Zhang].

\section{References}

1 Imamura H, Ohta T, Tsunetoshi K, Doi K, Nozaki K, Takagi Y, Kikuta K: Transdifferentiation of bone marrowderived endothelial progenitor cells into the smooth muscle cell lineage mediated by tansforming growth factor-beta1. Atherosclerosis 2010;211:114-121. 


\section{Cellular Physiology Cell Physiol Biochem 2015;35:1643-1653 \begin{tabular}{l|l} 
DOI: 10.1159/000373978 & (C) 2015 S. Karger AG, Basel
\end{tabular} and Biochemistry Published online: March 18, $2015 \quad$ www.karger.com/cpb \\ Zhang et al.: PI3K/Akt Signaling Regulates EndMT of EPCS}

2 Diez M, Musri MM, Ferrer E, Barbera JA, Peinado VI: Endothelial progenitor cells undergo an endothelialto-mesenchymal transition-like process mediated by TGFbetaR1. Cardiovasc Res 2010;88:502-511.

3 Kang HJ, Kim HS, Zhang SY, Park KW, Cho HJ, Koo BK, Kim YJ, Soo Lee D, Sohn DW, Han KS, Oh BH, Lee MM, Park YB: Effects of intracoronary infusion of peripheral blood stem-cells mobilised with granulocytecolony stimulating factor on left ventricular systolic function and restenosis after coronary stenting in myocardial infarction: The magic cell randomised clinical trial. Lancet 2004;363:751-756.

4 Rotmans JI, Heyligers JM, Verhagen HJ, Velema E, Nagtegaal MM, de Kleijn DP, de Groot FG, Stroes ES, Pasterkamp G: In vivo cell seeding with anti-CD34 antibodies successfully accelerates endothelialization but stimulates intimal hyperplasia in porcine arteriovenous expanded polytetrafluoroethylene grafts. Circulation 2005;112:12-18.

5 Klomp M, Beijk MA, Tijssen JG, de Winter RJ: One-year clinical outcome in an unselected patient population treated with the genous endothelial progenitor cell capturing stent. Catheter Cardiovasc Interv 2011;77:809-817.

6 Moonen JR, Krenning G, Brinker MG, Koerts JA, van Luyn MJ, Harmsen MC: Endothelial progenitor cells give rise to pro-angiogenic smooth muscle-like progeny. Cardiovasc Res 2010;86:506-515.

7 Cheng BB, Yan ZQ, Yao QP, Shen BR, Wang JY, Gao LZ, Li YQ, Yuan HT, Qi YX, Jiang ZL: Association of SIRT1 expression with shear stress induced endothelial progenitor cell differentiation. J Cell Biochem 2012;113:3663-3671.

8 Qiu C, Xie Q, Zhang D, Chen Q, Hu J, Xu L: GM-CSF induces cyclin D1 expression and proliferation of endothelial progenitor cells via PI3K and MAPK signaling. Cell Physiol Biochem 2014;33:784-795.

9 Obi S, Masuda H, Akimaru H, Shizuno T, Yamamoto K, Ando J, Asahara T: Dextran induces differentiation of circulating endothelial progenitor cells. Physiol Rep 2014;2:e00261.

10 Yang L, Guo XG, Du CQ, Yang JX, Jiang DM, Li B, Zhou WJ, Zhang FR: Interleukin-1 beta increases activity of human endothelial progenitor cells: Involvement of PI3K-Akt signaling pathway. Inflammation 2012;35:1242-1250.

11 Li J, Yu L, Zhao Y, Fu G, Zhou B: Thymosin beta4 reduces senescence of endothelial progenitor cells via the PI3K/Akt/eNOS signal transduction pathway. Mol Med Rep 2013;7:598-602.

12 Wang Y, Yan W, Lu X, Qian C, Zhang J, Li P, Shi L, Zhao P, Fu Z, Pu P, Kang C, Jiang T, Liu N, You Y: Overexpression of osteopontin induces angiogenesis of endothelial progenitor cells via the av $\beta 3 / \mathrm{PI} 3 \mathrm{~K} /$ Akt/eNOS/NO signaling pathway in glioma cells. Eur J Cell Biol 2011;90:642-648.

13 Zhang J, Zhang Z, Zhang DY, Zhu J, Zhang T, Wang C: MicroRNA 126 inhibits the transition of endothelial progenitor cells to mesenchymal cells via the PIK3R2-PI3K/Akt signalling pathway. PLoS One 2013;8:e83294.

14 Song K, Wang H, Krebs TL, Danielpour D: Novel roles of Akt and mTOR in suppressing TGF- $\beta$ /ALK5mediated Smad3 activation. EMBO J 2006;25:58-69.

15 Seoane J, Le HV, Shen L, Anderson SA, Massague J: Integration of Smad and forkhead pathways in the control of neuroepithelial and glioblastoma cell proliferation. Cell 2004;117:211-223.

16 Park SW, Zhou Y, Lee J, Lu A, Sun C, Chung J, Ueki K, Ozcan U: The regulatory subunits of PI3K, p85alpha and p85beta, interact with XBP-1 and increase its nuclear translocation. Nat Med 2010;16:429-437.

17 Lee J, Jung ID, Chang WK, Park CG, Cho DY, Shin EY, Seo DW, Kim YK, Lee HW, Han JW, Lee HY: P85 beta-PIX is required for cell motility through phosphorylations of focal adhesion kinase and p38 MAP kinase. Exp Cell Res 2005;307:315-328.

18 Foukas LC, Berenjeno IM, Gray A, Khwaja A, Vanhaesebroeck B: Activity of any class 1A PI3K isoform can sustain cell proliferation and survival. Proc Natl Acad Sci U S A 2010;107:11381-11386.

19 He J, de la Monte S, Wands JR: The p85beta regulatory subunit of PI3K serves as a substrate for pten protein phosphatase activity during insulin mediated signaling. Biochem Biophys Res Commun 2010;397:513-519.

20 Ueki K, Fruman DA, Yballe CM, Fasshauer M, Klein J, Asano T, Cantley LC, Kahn CR: Positive and negative roles of p85 alpha and p85 beta regulatory subunits of phosphoinositide 3-kinase in insulin signaling. J Biol Chem 2003;278:48453-48466.

21 Kessler A, Uphues I, Ouwens DM, Till M, Eckel J: Diversification of cardiac insulin signaling involves the p85 alpha/beta subunits of phosphatidylinositol 3-kinase. Am J Physiol Endocrinol Metab 2001;280:E65-74.

22 Conery AR, Cao Y, Thompson EA, Townsend CM, Jr., Ko TC, Luo K: Akt interacts directly with Smad3 to regulate the sensitivity to TGF-beta induced apoptosis. Nat Cell Biol 2004;6:366-372. 


\section{Cellular Physiology Cell Physiol Biochem 2015;35:1643-1653 \begin{tabular}{ll|l} 
and Biochemistry & $\begin{array}{l}\text { DOI: 10.1159/000373978 } \\
\text { Published online: March 18, } 2015\end{array}$ & $\begin{array}{l}\text { O) 2015 S. Karger AG, Basel } \\
\text { www.karger.com/cpb }\end{array}$ \\
\cline { 2 - 3 } &
\end{tabular} \\ Zhang et al.: PI3K/Akt Signaling Regulates EndMT of EPCS}

23 Accili D, Arden KC: FoxOs at the crossroads of cellular metabolism, differentiation, and transformation. Cell 2004;117:421-426.

24 Wang K, Li PF: Foxo3a regulates apoptosis by negatively targeting miR-21. J Biol Chem 2010;285:1695816966.

25 Li XL, Hara T, Choi Y, Subramanian M, Francis P, Bilke S, Walker RL, Pineda M, Zhu Y, Yang Y, Luo J, Wakefield LM, Brabletz T, Park BH, Sharma S, Chowdhury D, Meltzer PS, Lal A: A p21-ZEB1 complex inhibits epithelial-mesenchymal transition through the microRNA 183-96-182 cluster. Mol Cell Biol 2014;34:533550.

26 Wen FC, Chang TW, Tseng YL, Lee JC, Chang MC: hRAD9 functions as a tumor suppressor by inducing p21-dependent senescence and suppressing epithelial-mesenchymal transition through inhibition of slug transcription. Carcinogenesis 2014;35:1481-1490.

27 Wang P, Mao B, Luo W, Wei B, Jiang W, Liu D, Song L, Ji G, Yang Z, Lai YQ Yuan Z: The alteration of Hippo/ YAP signaling in the development of hypertrophic cardiomyopathy. Basic Res Cardiol 2014;109:435.

28 Varelas X, Samavarchi-Tehrani P, Narimatsu M, Weiss A, Cockburn K, Larsen BG, Rossant J, Wrana JL: The crumbs complex couples cell density sensing to Hippo-dependent control of the TGF-beta-Smad pathway. Dev Cell 2010;19:831-844.

29 Zeisberg EM, Tarnavski O, Zeisberg M, Dorfman AL, McMullen JR, Gustafsson E, Chandraker A, Yuan X, Pu WT, Roberts AB, Neilson EG, Sayegh MH, Izumo S, Kalluri R: Endothelial-to-mesenchymal transition contributes to cardiac fibrosis. Nat Med 2007;13:952-961.

30 Liu Z, Cai H, Zhang P, Li H, Liu H, Li Z: Activation of ERK1/2 and PI3K/Akt by IGF-1 on GAP-43 expression in DRG neurons with excitotoxicity induced by glutamate in vitro. Cell Mol Neurobiol 2012;32:191-200.

31 Boaglio AC, Zucchetti AE, Toledo FD, Barosso IR, Sanchez Pozzi EJ, Crocenzi FA, Roma MG: ERK1/2 and p38 MAPKs are complementarily involved in estradiol 17 $\beta$-D-glucuronide-induced cholestasis: Crosstalk with cPKC and PI3K. PLoS One 2012;7:e49255.

32 Akel S, Bertolette D, Ruscetti FW: Crosstalk between the Smad and the mitogen-activated protein kinase pathways is essential for erythroid differentiation of erythroleukemia cells induced by TGF-beta, activin, hydroxyurea and butyrate. J Leuk (Los Angel) 2013;1. 